\title{
Admiráveis andanças entre chitas e gasosas ${ }^{[1]}$
}

Impressive walkings among calicos and sodas

[ CAROL GARCIA $]^{[2]}$

Mestre em Comunicação e Semiótica pela PUC-SP e doutoranda no mesmo programa sob os auspícios da CAPES. É diretora científica da Modus Marketing e Semiótica, diretora internacional de pesquisas da Corporación Raiz Diseño e pesquisadora do CISC - Centro Interdisciplinar de Semiótica da Cultura e da Mídia junto ao CNPq. Co-autora do livro Moda é comunicação- experiências, memórias, vínculos (São Paulo: Anhembi Morumbi, 2005).

E-mail: carol.garcia@modusmkt.com

[resumo] Este artigo aborda a complexidade cultural que ambienta as principais regiões de comércio de artigos têxteis e de vestuário na cidade de São Paulo, tendo como ponto de partida o conceito de "mestiçagem", ou "mosaico movediço", conforme considerado por José Amálio Pinheiro, Nestor Garcia Canclini e Serge Gruzinski. 0 estudo avalia como se interconectam os signos que se avizinham nas situações de compra e venda de artigos populares para então relacionar moda e modos de vida na região. Percorrendo os caminhos do comércio popular, a análise vislumbra novos "modos de estar junto" que acompanham a dinâmica da vida social na metrópole.

\section{palavras-chave}

moda; modos de vida; mestiçagem; comércio popular; Rua 25 de Março.

[abstract] This article targets to analyse the cultural complexity that houses textile and clothing commercial zones in the city of São Paulo. Its approach is guided by the concept of mestiçagem" [3], or "movable mosaic" as considered by authors such as José Amálio Pinheiro, Nestor García Canclini and Serge Gruzinski. The study evaluates how neighbor signs interconnect themselves during the buying and selling of cheap articles in order to relate fashion to local lifestyle. Following the routes of popular commerce, this analysis foresees new ways of "being together" that go along with the dynamics of social life in a metropolis.

[key words] fashion; lifestyle; "mestiçagem";

popular commerce; 25 de Março street. 
nicacional em que é possivel vislumbrar novos "modos de estar junto", fato que nos parece perfeitamente possivel de contemplar no centro da capital paulista. Rennó (2006, p. 108) reafirma essa potencialidade quando coloca que "esta cidade oferece um campo riquíssimo para análise, por se tratar de um espaço que recebeu várias correntes migratórias em

São Paulo é uma das cidades que mais concentram os excessos e contradições dos grandes centros urbanos da América Latina: de uma parte, favorece o crescimento de situações de espaço e tempo tecno-hegemônicas, vinculadas ao projeto desenvolvimentista econômico-publicitário, que tende à adoção de planos e formatos lisos e ortogonais, condizentes com o ânimo rotariano e carreirista das classes profissionais e artisticas cuja formação é intrínseca às etapas políticas daquele projeto; de outra incorpora a proliferação de confluências migrantes e mestiças em espaços e tempos ao aberto, desdobrada pelos usos e trocas a partir das quais os sujeitos mesclam e traduzem objetos e imagens rugosos, sinuosos e dobráveis, através de enumerações e amplificações que encaixam o dispar, o paradoxal e o descontínuo. (PINHEIRO, 2006, p. 9)

Por volta de 6 horas da manhã de um dia qualquer do calendário, solados robustos escorregam sobre os paralelepípedos que aterram o outrora soberbo Rio Tamanduateí. Gotas de suor, exaustas e abundantes, descem das frontes e escorrem nas ladeiras. Mais frutas do que jamais portou o turbante da querida Carmen Miranda trocam de cores e de mãos logo ali, no Mercado da Cantareira. E antes mesmo do canto gregoriano dos monges marcar as horas na igreja pendurada na colina que se vê ao longe, miriades de bibelôs já se equilibram caoticamente no precipício das barracas multicoloridas.

Numerosas, elas invadem a passagem criada em 1859 para ligar a Ponte do Carmo ao antigo Porto de São Bento. Nesta mesma rua de desbotadas maravilhas arquitetônicas, que em 1865 passou a se chamar 25 de Março em homenagem à Primeira Constituição do Brasil[4], estampas extravagantes pingam das gravatas, bolsas e cintos que abarrotam as barracas dos ambulantes. Alguns têm olhos puxados, outros, a fala arrastada. Detalhes que apontam a longa jornada da terra natal até aquelas esquinas, nas quais vieram propor uma tessitura incomum.

Martín-Barbero (2005, p. 248) apresenta a cidade como um espaço comu- diferentes épocas (...)". Diante dessas premissas, parece-nos interessante percorrer as vielas entrelaçadas da região central de São Paulo e nelas observar como se relacionam e se inseminam mutuamente os textos da cultura. É nosso intuito avaliar em que medida se interconectam os signos que se avizinham nas situações de compra e venda de artigos populares nessa região da cidade.

No século XIX, o comércio de São Paulo estava concentrado na Rua Florêncio de Abreu. Mas a canalização e os aluguéis altos levaram comerciantes e novos imigrantes, a maioria deles sírios e libaneses, para mais perto do rio. No fim de 1893, existiam seis lojas no local: cinco armarinhos e uma mercearia. Oito anos depois, em 1901, já eram mais de 500 pequenas lojas. Todas muito prósperas porque os clientes tinham à disposição uma nova opção de transporte: 0 trem, que os deixava na Estação da Luz.

Desde então, a região de comércio da Rua 25 de Março é capaz de chacoalhar a familiaridade acomodada de certas relações com o mundo tanto quanto de refrescar o universo por vezes claustrofóbico e auto-referente da moda e dos modos de vida que ela impõe aos seus seguidores. É nesse espaço que a cultura jovem, voltando-se para o ideal de tornar impar aquilo que é massificado pela mídia, reencontrase com as antigas tradições do coser, do bordar, do rendilhar. E a linguagem hipnotizante das marcas européias e norteamericanas, fartamente divulgadas pela mídia impressa e eletrônica, é sabotada com réplicas inexatas delas próprias.

Tudo e todos se multiplicam infinitamente e é fácil perceber a vastidão dos números na própria pele. Pouco antes das 8, tecidos multicoloridos balançam das fachadas comerciais para roçar centenas de braços do lado de lá do balcão. Sem distinção de classe social, porque absolutamente todas elas se encontram e se conectam bem ali, consumidores carregados de pacotes galgam ladeiras em direção à estação de metrô chamada São Bento em homenagem à majestosa igreja vizinha.

Aos imigrantes vindos do Oriente Médio juntaram-se chineses, coreanos, mineiros e nordestinos que hoje fazem a rua ocupar o posto de maior espaço 
comercial a céu aberto da América Latina. São cerca de 3 mil empresas que empregam quase 40 mil pessoas. Esse enorme bazar é um elemento orgânico que ornamenta a cidade e reflete, majestoso, a grande diversidade brasileira. Nas suas entranhas constatamos com Gruzinski (2001, p. 28) que "(..) nada é inconciliável, nada é incompativel, mesmo se a mistura é por vezes dolorosa".

\section{Bendita chita!}

Das dobras sinuosas e deslizantes das esquinas, becos e galerias que serpenteiam à volta dos prédios da zona central de São Paulo saem passamanarias, fitilhos, flores e chitas prontos para se misturarem anonimamente, todo santo dia, juntando mães, filhas e netas em torno da máquina de costura. As sacolas plásticas transbordam e não é possível distinguir preciosidades de quinquilharias porque elas se enrodilham, ladinas, num mundo miscigenado.

Sob esse aspecto, entre tantas e tão prodigiosas misturas caboclas, talvez a mais expressiva seja aquela que se vê com grande freqüência nas prateleiras das lojas, nos tabuleiros dos ambulantes e sobre os corpos que lá circulam: a trama brejeira da chita. Originária da Índia e difundida no Brasil pelos portugueses, que a haviam herdado das expedições de Vasco da Gama, chita quer dizer variado, em sânscrito. É essa justamente sua maior qualidade: a diversidade de estampas que congrega, notadamente as florais, capaz de torná-la popular até mesmo na Inglaterra, onde responde pelo nome de chintz; ou na França, onde se estabeleceu na região da Provença. Prima pobre da finíssima cambraia de algodão, porém mais robusta e vistosa, a chita vira bolsa, blusinha ou minissaia e habita sem distinção os guarda-roupas de patroas e empregadas, adolescentes ou aposentadas. É recortada, aplicada e rebordada para renascer outra, fênix dos templos de corte e costura que circundam a 25 de Março.

Esse pano ordinário de algodão com estampa colorida cruzou oceanos carregando imagens estrangeiras. Mas as flores tímidas de padrões quase sempre listrados, dominadas pelos preceitos hindus e islâmicos (que proibem representações figurativas) encontraram na América não só algodões puros de trama ligeiramente aberta, os morins. Foi precisamente nessas paragens que outras flores, frutas e folhagens tropicais foram nela incorporadas e mesclaram-se ao imaginário de muitos povos para tornarem-se maiores e mais ousadas.

Assim, a história da chita brasileira, ou chitão, embora acompanhe a trajetória das Grandes Navegações, mesclase também às produções nativas das Américas, visto que seus povos já teciam algodões estampados em tons de vermelho, amarelo, azul, verde e preto. Paralelamente, reencontra-se com suas origens mouriscas na região Nordeste por intermédio dos malês (agrupados por sua identidade islâmica na Bahia) e com eles incorpora arabescos numa intersemiose contínua. Em terras americanas, 0 mimetismo aparente de chitas indianas, lusitanas, francesas e britânicas desafia completamente a noção de cópia fiel, visto que forma e conteúdo vão se alterando à medida que se entrelaçam sobre corpos caboclos em combinações extraordinárias.

Por conseguinte, assim como ocorreu com os exercícios de escrita dos indígenas que se tornaram calígrafos no México colonial de que nos fala Gruzinski, "desde os primeiros tempos a noção de cópia revelou-se extremamente elástica, variando da reprodução exata e da cópia fiel à interpretação inventiva" (2001, p. 106), na chita, as padronagens discretas de desbotadas anilinas européias diluíramse para explodirem estampas graúdas de cores vibrantes, tingidas com os corantes vegetais e a memória cultural dos povos autóctones. Mellão e Imbroisi (2005) esclarecem que 0 algodão, base de todas as chitas, era familiar aos índios quando Cabral aportou na Bahia. Eles o teciam em teares rústicos, feitos com galhos de árvores. Essa técnica familiar conheceu teares horizontais e técnicas de tecelagem européia no século XVI pelas mãos dos colonizadores portugueses. Alguns indios aprenderam essa arte importada da Europa, assim como, depois deles, as esposas dos donos de engenhos e as muIheres dos colonos imigrantes. Conforme Mellão e Imbroisi (2005, p. 60):

Os jesuitas decidiram que alguns padres deveriam aprender a tecer, com o objetivo de produzir os panos necessários para o consumo dos próprios religiosos e vestir os habitantes nativos, cuja nudez perturbava os propósitos missionários e colonizadores da Companhia de Jesus. 
das tendências de corpos, roupas e programas de comportamento, construídas com afinco por passarelas alheias.

São aquilo que Gruzinski (2001, p. 28) chama de "amálgamas de aparência desconcertante" cuja legitimidade naturalmente conquistada desloca a 25 de Março para o terreno do mítico, tornando-a imune ao passar do tempo e dos modis-

Assim, o tecido-imigrante foi tramando um mosaico mestiço. Sem cerimônia, penetra nos altares, mas também nas celebrações e nas passarelas brasileiras. Estampa os Autos de Natal e o maracatu, as festas dos santos de junho e os foliões de carnaval, as congadas e a São Paulo Fashion Week ${ }^{[5]}$, embutindo alegria na linguagem vestimentar pela gama intensa de combinações textuais. "(...) A chita está lá, com maior ou menor evidência, dividindo espaço com tiras de cetim ou servindo de base para bordados de paetês, miçangas e canutilhos" (MELLÃO; IMBROISI, 2005, p. 159).

As camadas culturais se sobrepõem e é impraticável pensar em cercas restritivas. Quando vemos a chita marcando os seios da Gabriela de Jorge Amado ou tremulando no varal da Clarissa de Érico Veríssimo melhor mesmo é entendê-la como mecanismo tradutório e aglutinador de tão variados percursos. E em nenhum lugar ela se assume com tanto vigor como no meio do povo que a transforma em saia rodada, em forro de colchão, em toalha de mesa ou em cortina da sala, inspirados tanto por Gisele Bündchen quanto por Chacrinha. 0 batalhão que avança sem trégua pela 25 de Março realiza nos artigos de chita a tessitura civilizatória. Melodramática e inclusiva: na cama, na mesa, no banho.

\section{Colcha de retalhos}

Martín-Barbero (2005, p. 34) nos fala do "(...) tecido de um novo tipo de espaço reticulado que transforma e ativa os sentidos do comunicar". É o territóriocidade em que emergem cenários fragmentados capazes de entrelaçar imagens de trabalho e prazer. Feito as flores das chitas estrangeiras que no Brasil cresceram e viraram chitões, a 25 de Março, onde são comercializadas, sintetiza esse espaço porque ganha corpo, volume e se agiganta, barulhenta e eletrizante. As referências históricas, construídas no alinhavo de vivências comunitárias, se dissolvem em cumplicidades capazes de dotar a região de legitimidade no território vestimentar. As histórias penduradas em suas esquinas, advindas da memória afetiva, traçam uma geopolítica que desmascara a homogeneidade mos. Isso porque tal maneira de comungar experiências de várias gerações, ao invés de meramente reproduzir os modos de costurar sofisticados das grifes estrangeiras divulgadas pela indústria do entretenimento, pelo jornalismo e pela publicidade, com elas compartilha fragmentos de saberes domésticos. Uma vez revolvidos nos arredores da 25 de Março, descortinam uma paisagem de surpreendentes possibilidades e fascinam milhares de transeuntes.

Nem sempre foi assim, evidentemente. Das primeiras décadas do Brasil colônia até o fim do século XIX, a moda francesa desembarcou nos portos do Rio de Janeiro, de Belém, do Recife, de Paranaguá e de Santos trazendo os figurinos, os nomes das lojas (como Paris N'América e Casa Louvre), o que fazer e o que vestir, na maioria das vezes ainda em completa desarmonia em relação ao clima e às circunstâncias sociais brasileiras. Foi o contínuo desenvolvimento da máquina de costura, bem como sua paulatina introdução no mercado doméstico pelos diversos povos que aqui se estabeleceram, que viabilizou a reprodução de roupas de um modo jamais pensado, quando o coser era ainda inteiramente manual. Imigrantes proletários, dentre os quais muitos ligados à indústria têxtil (vindos da Europa Oriental e, principalmente, da Itália), chegavam nos mesmos navios que as novidades importadas, seguindo viagem por via férrea até os núcleos urbanos, onde se instalavam perto das estações de trem (BRESSER, 2001).

Exatamente por esse motivo, a moda espalhou-se em torno da Estação da Luz, fazendo das ruas ao seu redor passarela de gente animada a comprar e a vender abundantemente não só panos e aviamentos, mas guarda-roupas inteiros para vestir toda a família. Da cabeça aos pés, da praia ao baile de formatura. Há muitas razões para isso, boa parte delas histórica. Entre 1880 e 1890, os bairros do Bom Retiro e do Brás eram o endereço preferido da maioria dos que aqui desembarcavam dada a facilidade de transporte. Primeiro foram os italianos. Depois vieram os judeus, os gregos e por fim os coreanos somar com os índios e os negros. Tal engaste 
de culturas promove uma dissonância na linearidade da moda: é o que faz da chita lugar da mestiçagem.

A princípio, mascates russos moradores da região do Bom Retiro, denominados clientelchiks, vendiam tecidos, roupas e acessórios de chita à prestação para as classes populares da capital e do interior paulista, dando impulso à divulgação da fama de "roupa boa e barata" nas zonas visitadas. Em 1910, o bairro concentrava cerca de $70 \%$ da força de trabalho do setor têxtil, composta por cerca de 10 mil operários (80\% de italianos, $11 \%$ de portugueses, 5\% de espanhóis), e até os anos 1940 abrigou a face industrial de São Paulo. A área sofreu o impacto das transformações tecnológicas e de gestão empresarial pós-Segunda Guerra Mundial, determinando a obsolescência de importantes empresas, como o Cotonifício Crespi e a Indústria Matarazzo, mas foi aos poucos recuperando o fôlego original e tornouse o grande pólo que hoje aglutina comerciantes de artigos de vestuário.

E é esse mesmo engaste de culturas que atualmente desafia o purismo de tendências de moda impostas pela lógica de mercado e faz a região ter brilho próprio. Vitrinas enormes e manequins sorridentes exibem pilhas estratosféricas de camisetas, vestidos, saias ou o que a novela das 8 tiver exibido nas ancas das estrelas ainda ontem à noite, provando que a moda dessas paragens não tem sotaque preciso. Brás e Bom Retiro afirmam a exuberância estética que impregna um dia-a-dia brejeiro incorporando o trivial à sua maneira. Mesclam o improvisado, o singelo e o banal (como o visual dos artistas de telenovelas) aos repertórios lacrados, eruditos e hegemônicos da cultura "oficial" de moda (como as tendências exibidas nas passarelas mundiais) e, conseqüentemente, estimulam miscigenações, fazendo com que o jeito de vestir que propõem nasça de um modo de costurar aberto e permeável.

No labirinto do Bom Retiro, desde a década de 1950, multiplicam-se as pequenas oficinas de roupas finas e os estabelecimentos comerciais de atacado e varejo. Nessa época surgiram as primeiras galerias e os centros comerciais, com centenas de lojas cada um, principalmente de artigos de vestuário. Muitas delas mantêm nos fundos suas próprias oficinas de costura ou fábricas de malhas, gravatas e artigos semelhantes. A maior parte do comércio, desde o início, ficou concentrada ao longo dos seis quarteirões da Rua José Paulino, que até 1916 chamava-se Rua dos Imigrantes.

Bresser (2001) destaca que outras vias do bairro descobriram, com o correr do tempo, que a vocação da região como um todo era virar um grande centro de negócios de roupas e tecidos. $\mathrm{Na}$ Rua Aimorés instalaram-se inicialmente fábricas de camisas e pulôveres. Aos poucos, a rua foi se transformando num dos principais endereços para quem hoje quer comprar moda no atacado. A Rua Itaboca também mudou. Rebatizada de Professor Cesare Lombroso, é agora outro corredor imprescindível para quem pretende desvendar a região.

0 Bom Retiro firmou-se no comércio de roupas prontas e, com tantas migrações, não mudou sua natureza mestiça. Atualmente, 70\% do comércio do bairro pertence aos coreanos, que chegaram nos anos 1960 e 1970, incentivando o crescimento local graças aos preços populares, mas também às inúmeras viagens de pesquisa e informação de moda que possibilitaram outros intercâmbios e incorporações. Os coreanos agregaram desfiles a céu aberto e ampla parceria entre lojistas organizados em associações de vizinhança, provocando aproximações. "O segredo, segundo Anastassiadis [empresário grego também estabelecido na região], está no mix de empresas" (BRESSER, 2001, p. 46). Ou seja, precisamente na mistura.

Esse é o principal motivo pelo qual o bairro hoje chega a concentrar 1.200 pontos-de-venda e a receber em média 30 mil pessoas por dia. Ao todo, as confecções da região atingem a venda de 2 bilhões de peças/ano, as quais consomem 70 toneladas de tecido/ano. Existe fartura, abundância e excesso em constante ebulição, contrapondose à mesmice repetitiva das vitrines de shopping centers, cuja padronização arquitetônica provocada pela presença de cadeias de lojas é asséptica e monótona.

\section{Jesus em lata}

Rennó (2006, p. 107) afirma que se deve entender o comércio como um sistema de relações. É interessante observar que parte da vibração dessas ruas está precisamente nas distintas séries culturais que ali se misturam produzindo significação. Em vez de permanecerem 
Iho nacional no mercado das borbulhas engarrafadas sem aderir ao sabor artificial de baunilha. Sua fórmula, à base de canela natural, garante o perfume, 0 colorido e uma legião de fiéis.

A situação nos permite observar que as séries culturais são estruturas em constante movimento que resultam num teci-

isoladas em áreas restritas como acontece nos shopping centers de topologia norte-americana, a montagem discursiva dessas zonas comerciais convida a intervenções e aproximações. Nelas instalam-se, por exemplo, outros fornecedores de serviços necessários ao atendimento dos compradores que vêm de longe percorrer os atacadistas, misturando-se a eles indistintamente.

Não se estabelecem, por exemplo, as famigeradas praças de alimentação típicas dos centros comerciais enlatados. Ao contrário, abundam os restaurantes por quilo, os bares, as padarias, as lanchonetes e os camelôs que vendem balas a granel, milho verde em sacas, frutas aos bocados, café de coador em garrafas térmicas, bolo caseiro em fatias e refrigerantes variados. Não apenas aqueles de marcas famosas, mas, sobretudo, alguns de nomes exóticos e fabricantes desconhecidos, das chamadas tubainas aos sabores que combinam frutas típicas brasileiras às borbulhas da água gaseificada. São bebidas vendidas em latas, em garrafas plásticas de um ou mais litros e até em vasilhames de cerveja sem qualquer identificação, para consumo imediato, ali mesmo em meio às pechinchas.

A maioria dessas gasosas é produzida com fórmulas brasileiras, muitas vezes com ervas locais, como o guaraná Bacana, que fez do adjetivo nome próprio. É também o caso do Mineirinho, fabricado em Niterói, que utiliza concentrado da planta chapéu-de-couro, e da Gengibirra, produzida na periferia de Curitiba, à base de gengibre. Nas esquinas do Bom Retiro é possível encontrá-las disputando mercado com a cajuína São Geraldo, de amarelo estonteante, produzida com suco natural de caju e água gaseificada em Juazeiro do Norte e "exportada" para São Paulo no lastro dos migrantes nordestinos.

Esse também é dos poucos lugares em que se pode saborear a vibração rosa-choque do guaraná Jesus que, sem ser pirata, é trazido de São Luís do Maranhão. Isso porque, graças aos caprichos do fabricante local de Coca-Cola, tem produção restrita ao abastecimento da região onde nasceu. Criado em 1920 pelo farmacêutico Jesus Gomes, é orgudo complexo e descentralizado, continuamente reformulado por múltiplos agentes. As gasosas podem ser consideradas mosaicos movediços de beber, assim como as chitas são mosaicos movediços de vestir. Isso porque apresentam deliciosa evolução da relação entre significante e significado quando formam essa retícula sinuosa nas ruas do bairro que inventa moda sem nelas estar.

Para Rennó (2006, p. 107), "os significados presentes ali [no âmbito das zonas comerciais paulistanas de bairro] são múltiplos e refletem, na sincronia, o micro e o macro contexto histórico da urbe". Sob esse aspecto, podemos refletir que o mundo visto pelas lentes da 25 de Março, do Brás e do Bom Retiro estrutura coerência interna capaz de conferir aos produtos que ali circulam valor e significação. Como na antropofagia, prática dos índios tupis que consistia em devorar guerreiros valentes de outras tribos, noções como conforto, luxo, elegância e, sobretudo, tradição, tão arraigadas em conceitos estáticos, são revolvidas à exaustão para ressurgirem com outro viço, convertidas em estratégias de atração sobre o consumidor. São misturas que desenquadram das variações rítmicas e direcionadas dos grandes centros para a periferia não só os modos de vestir e de beber, mas, de maneira mais ampla, os modos de consumir e de viver. Quando admitimos que certo modo de vida no Brasil brota mesmo é das muitas mesclas, podemos concluir com Canclini (2006, p. 280) que:

0 popular se coloca em cena (...) com o sentido contraditório e ambíguo dos que padecem a história e ao mesmo tempo lutam nela, dos que vão elaborando, como em toda tragicomédia, os passos intermediários, as astúcias dramáticas, os jogos paródicos que permitem aos que não têm essa possibilidade de mudar radicalmente o curso da obra, manejar os interstícios com parcial criatividade e brilho próprio.

É neste grupo, vivendo na tensão dialética entre a prescrição e o caos reordenador, que podemos situar o formigueiro laborioso dos comerciantes e consumidores da região central de São 
Paulo, impetuosos e ávidos por gerar outra política de existência: um modo de vida/moda impregnado de frescor, porque construído na confluência de questionamentos. Em seu idear constante borbuIham metamorfoses de um processo que se administra incansavelmente no diaa-dia, no qual subjazem reticências que aspiram a um novo início.

Fundamentada em tramas de vibração contagiante, a moda nascida desse caldeirão cosmopolita jamais resvala nas caricaturas de trajes típicos e de outras heranças folclóricas. A desigualdade da distribuição de renda entre consumidores e as disparidades dela decorrentes, assim como a interatividade intensa de culturas diversas e a forte assimilação da programação televisiva, as quais facilmente poderiam encadear situações de conflito, são, ao contrário, friccionadas. E delas transborda um jeito de vestir pulsante, que embaralha a tediosa mesmice, como faz o chitão brasileiro ao incorporar outras padronagens ao chintz ou a tubaína com sotaque caipira diante da globalizada Coca-Cola. Nas dobraduras desse modo de costurar, referências perfilam traços distintivos de uma estética viçosa, por vezes irrequieta e sempre engenhosa, que encarna toda a heterogeneidade de que, em suma, é feito o Brasil.

\section{Notas}

[1] Este artigo integra as pesquisas de meu projeto de doutorado, orientado pelo Prof. Dr. Norval Baitello Júnior, no qual estudo as migrações de imagens entre culturas com foco no padrão ornamental floral das chitas populares.

${ }^{[2]}$ Foi a escritora mexicana Elena Garro, no sublime romance Los Recuerdos del Porvenir, quem primeiro disse que "yo solo soy memória y la memória que de mi se tenga" (Editorial Joaquin Mortiz, 2006, p.1). Com as melhores lembranças dos que, com a grandeza dos gestos, inspiraram este trabalho, agradeço ao Prof. Dr. José Amálio Pinheiro, mestre na arte da vida, cujos luminosos ensinamentos transformam continuamente meu olhar, e dedico a J., alma viajante, cuja sensibilidade me faz despertar para a beleza encantadora das palavras, das memórias e de suas muitas esquinas.

${ }^{[3]}$ The word mestiçagem eventually could be translated into "mixing", although justice should be done that it is much more than that, for it includes, among others, cultural, ethical, political and physical aspects of daily life in permanent touch and evolution.

${ }^{[4]}$ A Primeira Constituição do Brasil foi outorgada justamente no dia 25 de Março de 1824 por D. Pedro I.

[5] São Paulo Fashion Week, Calendário Oficial da Moda Brasileira, é hoje o maior evento de moda do país e nele marcas como Zapping, Ronaldo Fraga, André Lima, Karlla Girotto, entre outras, já apresentaram criações em chita.

\section{REFERÊNCIAS}

BRESSER, Deborah. "Todos os sotaques da Moda de São Paulo". In: CASTILHO, Kathia; GARCIA, Carol (org.) Moda Brasil - fragmentos de um vestir tropical. São Paulo: Anhembi Morumbi, 2001.

CANCLINI, Nestor Garcia. Culturas hibridas - estratégias para entrar e sair da modernidade.

Trad. Ana Regina Lessa; Heloísa Pezza Cintrão. 4ª ed. São Paulo: Edusp, 2006

GARRO, Elena. Los recuerdos del porvenir. Cidade do México: Editorial Joaquín Mortíz, 2006

GRUZINSKI, Serge. O pensamento mestiço. São Paulo: Companhia das Letras, 2001.

MARTÍN-BARBERO, Jesús. Ofício de cartógrafo - travesías latinoamericanas de la comunicación en la cultura. Santiago: Fondo de Cultura Económica, 2005.

MELLÃO, Renata; IMBROISI, Renato. Que chita bacana. São Paulo: A Casa- Museu do Objeto Brasileiro, 2005.

PINHEIRO, José Amálio. "Prólogo". In: RENNÓ, Raquel. Do mármore ao vidro:mercados públicos e supermercados, curva e reta sobre a cidade. São Paulo: Annablume, 2006.

RENNÓ, Raquel. Do mármore ao vidro - mercados públicos e supermercados, curva e reta sobre a cidade. São Paulo: Annablume, 2006 